\title{
Development of a mass spectrometry method for the determination of a melanoma biomarker, 5-S-cysteinyldopa, in human plasma using solid phase extraction for sample clean-up
}

\author{
Gaëlle B. Martin ${ }^{\mathrm{a}}$, Patrice Chiap ${ }^{\mathrm{d}}$, Philippe Paquet ${ }^{\mathrm{c}}$, Gerald Pierard ${ }^{\mathrm{c}}$, \\ Pascal de Tullio ${ }^{\mathrm{e}}$, Yves Martin ${ }^{\mathrm{a}}$, Eric Rozet ${ }^{\mathrm{b}}$, Philippe Hubert ${ }^{\mathrm{b}}$, \\ Jacques Crommen ${ }^{\mathrm{a}}$, Marianne Fillet ${ }^{\mathrm{a}, *}$ \\ a Laboratory of Analytical Pharmaceutical Chemistry, Bioanalytical Chemistry Research Unit, Institute of Pharmacy, \\ University of Liège, CHU, B36, B-4000 Liège, Belgium \\ ${ }^{\mathrm{b}}$ Laboratory of Analytical Chemistry, Bioanalytical Chemistry Research Unit, Institute of Pharmacy, \\ University of Liège, CHU, B36, B-4000 Liège, Belgium \\ ${ }^{\mathrm{c}}$ Department of Dermathopathology, $\mathrm{CHU}$, Liège, Belgium \\ d Advanced Technology Corporation (A.T.C.), CHU, B23, B-4000 Liège, Belgium \\ ${ }^{\mathrm{e}}$ Laboratory of Medicinal Chemistry, Institute of Pharmacy, University of Liège, \\ CHU, B36, B-4000 Liège, Belgium
}

Available online 29 December 2006

\begin{abstract}
5-S-cysteinyldopa is a well-known pigment intermediate and analysis of its plasma concentration is interesting for the early diagnosis, as well as for evaluation of treatment and follow-up of malignant melanoma. A determination method of 5-SCD in human plasma was developed using solid phase extraction (SPE) on disposable cartridges and liquid chromatography electrospray mass spectrometry (LC-ESI-MS-MS). Compound's sensitivity to light and oxidation requires the addition of anti-oxidative agents (AO), to work in acidic media at $4{ }^{\circ} \mathrm{C}$ and to avoid light exposure of samples since blood collection. Different solid phases involving covalent binding to phenylboronic groups or dual retention mechanisms were evaluated and extraction cartridges containing both hydrophobic and strong cation exchange functionalities were finally selected. The LC separation of 5-SCD from endogenous catecholamines was achieved by gradient elution on a C18 stationary phase. 5-SCD was detected by multiple reaction monitoring (MRM) performed on ES(+) generated ions. Finally, the method was prevalidated in the lower ng/ml range. Good results with respect to accuracy, trueness and precision were obtained.
\end{abstract}

(C) 2006 Elsevier B.V. All rights reserved.

Keywords: 5-S-cysteinyldopa; HPLC-MS; Plasma; Melanoma marker

\section{Introduction}

Incidence of malignant melanoma is in constant progression in caucasian population. This disease is characterised by a great metastatic potential and therefore by a very unfavourable prognosis. Malignant melanoma is a tumour which develops at the expense of the melanocytical cell system. It affects predominantly the skin and more rarely the nails or the mucous membranes. Considering that no therapy has shown its efficiency on the survival of patients in the metastatic phase, the early detec-

\footnotetext{
* Corresponding author. Tel.: +32 4366 4354; fax: +3243664347.

E-mail address: Marianne.fillet@ulg.ac.be (M. Fillet).
}

tion of melanomas seems to be of the utmost importance as well as the development of preventive measures particularly in terms of photoprotection [1-4].

Among the known plasmatic biomarkers of melanoma, 5$S$-L-cysteinyl-L-dopa (5-SCD) seems to constitute an excellent detector of metastasis and parameter of disease progression, showing significant elevation with the occurrence of metastasis and with the progression of the disease earlier than physical, radiological or other laboratory investigations [5-9].

Oxidation of cysteinyldopa isomers in melanocytes leads to the production of pheomelanin, a yellow to reddish melanin, but a significant portion of cysteinyldopa escapes from melanocytes, especially melanoma cells. It is thus possible to estimate the 
progression of melanoma by measuring the concentration of $5-\mathrm{SCD}$ in blood or urine [1,6-21].

Since then, levels of 5-SCD were always measured by high-performance liquid chromatography with electrochemical detection [7,21-23]. Concerning the extraction of 5-SCD from biological matrix, alumina extraction [9-13] was very often applied prior to HPLC analysis, sometimes coupled with an additional liquid-liquid extraction step. Enrichment methods with phenylboronate affinity gel have also been described [14,15]. Finally, phenylboronic acid SPE cartridges were successfully used by Hartleb and Huang [16,17].

For the first time we have developed a HPLC-mass spectrometry (MS) method for the determination of 5-SCD in plasma. High sensitivity and specificity were obtained using multiple reaction monitoring $(\mathrm{MRM})$ performed on $\mathrm{ES}(+)$ generated ions. Several types of automated solid phase extraction procedures were tested in order to extract 5-SCD from plasma in a MS compatible manner. The sensitivity of the compound of interest to oxidation and light exposure has been taken into account. The entire method was then prevalidated at the nanogram level.

\section{Materials and methods}

\subsection{Chemicals and reagents}

5-SCD was prepared as previously described [24,25]. $\alpha$ Methyldopa was supplied by Acros organics (NJ, USA). Their chemical structures are presented in Fig. 1. Epinephrine was obtained from Bufa (Netherland) and norepinephrine from Sigma-Aldrich (St. Louis, MO, USA). Dopamine, levodopa, formic acid (98-100\%) and ammonia solution (28-30\%) were from Acros organics (NJ, USA). Hydrochloric acid (37\%), methanol HPLC grade and acetic acid (100\%) were supplied by Merck (Darmstadt, Germany). Water and methanol of LC-MS grade were obtained from Biosolve (Netherland). Ascorbic acid was from Certa (Braine-l' Alleud, Belgium) and $o$ phosphoric acid (minimum 85\%) from UCB (Leuven, Belgium). All reagents were of analytical grade. Water used in most experiments was of Milli-Q quality (Millipore, Bedford, MA, USA). Oasis MCX sorbent $(30 \mathrm{mg} / \mathrm{ml})$ were obtained from Waters (Milford, MA, USA). Other sorbents, namely Oasis MAX $(30 \mathrm{mg} / \mathrm{ml})$ from Waters, Bond Elut PBA $(100 \mathrm{mg} / \mathrm{ml})$ from Var-

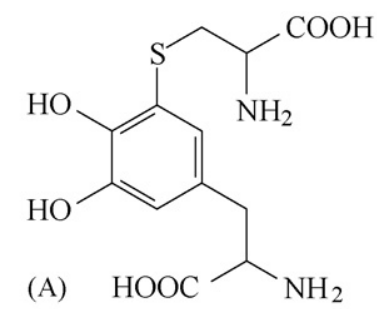

(B)

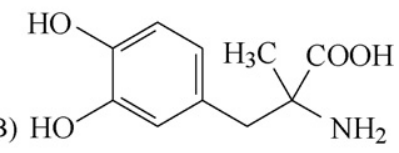

Fig. 1. Chemical structures of cysdopa (A) and $\alpha$-methyldopa (B). ian (Harbor City, CA, USA) and Isolute HCX-3 (130 mg/ml) from International Sorbent Technology (Mid Glamorgan, UK), were also tested. Nitrogen (alphagaz 1) and argon (alphagaz 2) were purchased from Air Liquide (Milmort, Belgium).

\subsection{Apparatus}

Experiments were carried out with a HPLC equipped with a binary pump, an autosampler, a thermostated column compartment and a diode-array detector, all HP series 1100 from Hewlett-Packard (Waldbronn, Germany). The LC model coupled to the MS system possessed a quaternary pump, a vacuum degasser, an autosampler and a thermostated column compartment (HP 1100 series, Agilent Technologies, Waldbronn, Germany). A LC Chemstation (Hewlett-Packard) was used for instrument control, data acquisition and data handling, when UV detection was performed. MS detection was carried out using an Ultima triple quadrupole instrument (Micromass, Manchester, UK) operating under MassLynx 3.5 and configured with a Z-spray electrospray ionization source. The separation was performed on an Atlantis dC18 column $(100 \mathrm{~mm} \times 2.1 \mathrm{~mm}$, i.d.; particle size: $3 \mu \mathrm{m}$ ) from Waters. An Alltima HP C18 Amide $(250 \mathrm{~mm} \times 3.0 \mathrm{~mm}$, i.d.; particle size: $5 \mu \mathrm{m})$ from Alltech Associates Inc. (Deerfield, IL, USA) was also tested. The ASPEC system (automated sample preparation with extraction cartridges) from Gilson (Villers-le-Bel, France) consisted of a sample processor equipped with an $x y z$-motion robotic arm, a 401C dilutor/pipettor connected to a needle attached to the robotic arm and a set of rack and accessories for handling disposable extraction cartridges, samples and solvents. A 722 keypad software from Gilson was used for the control of the ASPEC system.

The e.noval ${ }^{\circledR}$ software (Arlenda, Belgium) was used to obtain the accuracy profiles as well as all prevalidation results.

\subsection{Chromatographic conditions}

The chromatographic separation of 5-SCD from endogenous catecholamines was achieved by gradient elution on a C18 stationary phase compatible with mobile phases with very low content of organic modifier. The mobile phase consisted for one part of $0.1 \%(\mathrm{v} / \mathrm{v})$ formic acid in water and for the other part of $0.1 \%(\mathrm{v} / \mathrm{v})$ formic acid in methanol. The content of organic modifier increased from 0 to $10 \%$ in $10 \mathrm{~min}$. Prior to use, mobile phases were degassed for $15 \mathrm{~min}$ in an ultrasonic bath. The chromatographic separation was performed at $20^{\circ} \mathrm{C}$ using a constant flow rate of $0.25 \mathrm{ml} / \mathrm{min}$. The injected volume was $20 \mu \mathrm{l}$ and the thermostated autosampler was set to $10^{\circ} \mathrm{C}$.

\subsection{Extraction technique}

\subsubsection{Final conditions on Oasis MCX cartridges}

The automatic procedure was started by the washing of the needle of the dilutor with a mixture of methanol and water $(10: 90, v / v)$. Between each step of the sample handling, the needle was rinsed with the same volume of this methanol-water mixture and an air bubble was generated in the transfer 
tubing before aspiration of other liquids in order to avoid cross-contamination. The following optimized SPE procedure was then applied for Oasis MCX cartridges: (i) conditioning of the extraction support (flow rate: $1.5 \mathrm{ml} / \mathrm{min}$; air volume: $1 \mathrm{ml}$ ): the sorbent was treated first by $1.0 \mathrm{ml}$ of methanol and then by $1.0 \mathrm{ml}$ of $0.1 \mathrm{M}$ hydrochloric acid. (ii) Loading of the plasma sample (flow rate: $0.18 \mathrm{ml} / \mathrm{min}$; air volume: $1 \mathrm{ml}$ ): a $2 \mathrm{ml}$ volume of acidified plasma sample was applied on the sorbent at the minimum dispensing flow rate in order to maximize the analyte retention. (iii) Washing (flow rate: $1.5 \mathrm{ml} / \mathrm{min}$; air volume: $1 \mathrm{ml}$ ): the sorbent was successively washed with $1.0 \mathrm{ml}$ of $0.1 \mathrm{M}$ hydrochloric acid and $1.0 \mathrm{ml}$ of methanol. (iv) Elution (flow rate: $1.5 \mathrm{ml} / \mathrm{min}$; air volume: $1 \mathrm{ml}$ ): $5-\mathrm{SCD}$ and $\alpha$-methyldopa were eluted from the sorbent with $0.5 \mathrm{ml}$ of the mixture methanol/water/ammonia (80:10:10, v/v/v) containing $0.1 \%$ ascorbic acid. This step was followed by the automated acidification of the eluate with $100 \mu$ l of formic acid in order to minimize the degradation of the catecholamines by oxidation. The eluate was collected and gently evaporated to dryness under a nitrogen stream. The dried extracts were finally reconstituted in $500 \mu \mathrm{l}$ of water containing $0.1 \%$ formic acid and $0.1 \%$ ascorbic acid, the solution was submitted to centrifugation and the supernatant was injected into the LC system.

\subsubsection{Initial conditions for Bond Elut PBA cartridges}

Conditioning of the sorbent was performed in applying methanol followed by Tris buffer $(1.0 \mathrm{ml}$ each); then, the sample constituted by 5 -SCD and $\alpha$-methyldopa $(10 \mu \mathrm{g} / \mathrm{ml}$ each) in Tris buffer was loaded on the support; Tris buffer followed by a mixture of methanol/Tris buffer 5:95 (v/v) $(1.0 \mathrm{ml}$ each) was used for the washing step and finally, elution of the analytes was possible with $0.3 \mathrm{ml}$ of a mixture of $3 \mathrm{M}$ formic acid $+4 \mathrm{mM}$ GSH (pH 1.5)/acetonitrile 95:5 (v/v).

\subsubsection{Initial conditions for Oasis MAX cartridges}

The stationary phase was conditioned by $1.0 \mathrm{ml}$ methanol followed by $1.0 \mathrm{ml}$ of $50 \mathrm{mM}$ acetate buffer $(\mathrm{pH}$ 9); loaded with a solution of 5-SCD and $\alpha$-methyldopa $(10 \mu \mathrm{g} / \mathrm{ml})$ in $50 \mathrm{mM}$ acetate buffer ( $\mathrm{pH} 9)$ and washed by $1.0 \mathrm{ml}$ of the same buffer. The compounds of interest were eluted by $0.5 \mathrm{ml}$ of a solution of methanol containing $2 \%$ acetic acid.

\subsubsection{Initial conditions for Isolute HCX-3 and Oasis MCX cartridges}

Methanol followed by a $50 \mathrm{mM}$ formate buffer $(\mathrm{pH} 2.5)$ was used for support conditioning. The sample loaded was composed of a formate buffer ( $\mathrm{pH}$ 2.5) containing the 5-SCD and its internal standard at a concentration of $10 \mu \mathrm{g} / \mathrm{ml}$ each. The washing of the sorbent was performed with $1.0 \mathrm{ml}$ of the $50 \mathrm{mM}$ formate buffer ( $\mathrm{pH} 2.5$ ) and, finally, the analytes were eluted by $0.5 \mathrm{ml}$ of a solution of methanol containing $2 \%$ of ammonia.

\subsection{Mass spectrometry detection}

Mass spectrometric detection was carried out using an Ultima triple quadrupole (Micromass) apparatus equipped with an electrospray interface operating in the positive ion mode. 5-SCD and its internal standard were detected by multiple reaction monitoring (MRM) performed on electrospray positive generated ions. The source was heated up to $120^{\circ} \mathrm{C}$ and the desolvation temperature was fixed at $450^{\circ} \mathrm{C}$. The applied voltages for the capillary and the cone were, respectively, $3.0 \mathrm{kV}$ and $30 \mathrm{~V}$ and the gas flow rates were set at $160 \mathrm{l} / \mathrm{h}$ for the cone and $750 \mathrm{l} / \mathrm{h}$ for the desolvation. The mass spectrometer generated and selected the pseudomolecular ions $\left[\mathrm{MH}^{+}\right]$at $m / z, 317$ for 5-SCD and 212 for $\alpha$-methyldopa by the intermediate of the first quadrupole mass filter (Q1). The fragmentation was then performed in the collision cell (Q2) by applying a collision energy of $25 \mathrm{eV}$. Signals were monitored from the third quadrupole (Q3) at $\mathrm{m} / \mathrm{z} 155$ and 166 for 5-SCD and internal standard, respectively.

\subsection{Standard solutions}

\subsubsection{Solutions used for method development with UV detection}

A solution of epinephrine, norepinephrine, dopamine, levodopa, 5-SCD and $\alpha$-methyldopa was prepared by dissolving the appropriate amounts of analytes in $10 \mathrm{mM}$ hydrochloric acid solution in order to obtain a concentration of $0.4 \mathrm{mg} / \mathrm{ml}$ for each catecholamine. From this solution, diluted solutions were prepared in the same media to reach final concentrations of 40 and $200 \mu \mathrm{g} / \mathrm{ml}$. Samples which were submitted to the extraction procedure (water or plasma acidified by $2 \%$ phosphoric acid) were spiked with $25 \mu \mathrm{l}$ of these three solutions.

\subsubsection{Solutions used for method development with MS detection}

Two stock solutions of 5-SCD and $\alpha$-methyldopa were prepared by dissolving the appropriate amounts of analytes in $10 \mathrm{mM}$ hydrochloric acid solution in order to obtain a concentration of $0.3 \mathrm{mg} / \mathrm{ml}$. These stock solutions were diluted in the same media to reach concentrations ranging from 60 to $6000 \mathrm{ng} / \mathrm{ml}$. $25 \mu \mathrm{l}$ of these diluted solutions was spiked in the acidified plasma samples before the extraction procedure.

Ascorbic acid stock solution was prepared by dissolving $800 \mathrm{mg}$ of the anti-oxidative compound in $10 \mathrm{ml}$ of $10 \mathrm{mM}$ hydrochloric acid solution.

\subsubsection{Solutions used for prevalidation phase}

An appropriate amount of 5-SCD was dissolved in $10 \mathrm{mM}$ hydrochloric acid solution in order to obtain a concentration of $32 \mu \mathrm{g} / \mathrm{ml}$ (stock solution). Dilutions of the stock solution were performed to reach final concentrations of 64, 192, 384, 4000 and $8000 \mathrm{ng} / \mathrm{ml}$. In the same way, stock and diluted solutions of $\alpha$-methyldopa were prepared in order to obtain a final concentration of $2000 \mathrm{ng} / \mathrm{ml}$. All diluted solutions were freshly prepared.

Daily, plasma stored at $-80{ }^{\circ} \mathrm{C}$ was first thawed at ambient temperature in the darkness and centrifuged at $4500 \mathrm{rpm}$ for 10 min. A mixture containing $25 \mu \mathrm{l}$ of the ascorbic acid stock solution, $25 \mu \mathrm{l}$ of the 5 -SCD solution and $25 \mu \mathrm{l}$ of the internal standard solution was prepared. Plasma previously acidified by $2 \%$ phosphoric acid was then added up to $1 \mathrm{ml}$ and the final sample was mixed. The spiked plasma samples were then introduced into tubes of the ASPEC sample processor. Two calibration 
curves ranging from 1.6 to $200 \mathrm{ng} / \mathrm{ml}(k=2)$ were performed in the matrix, every one by using new diluted solutions and each calibration standard was injected in duplicate $(n=2)$. In addition, daily, a calibration curve without the matrix was directly injected into the LC-MS-MS system.

\section{Results and discussion}

\subsection{Optimization of mass spectrometric and chromatographic conditions}

MS detection parameters were optimized by direct injection of reference compounds in solution using the electrospray interface in the positive mode of ionisation. Values for cone and capillary voltages, cone and desolvation gas flows and temperatures were determined in order to obtain the best signal for 5-SCD in particular (cf. Section 2). The highest protonated molecular ions generated under a stable spray, corresponding to the $[\mathrm{M}+\mathrm{H}]^{+}$ionic species, were detected at $\mathrm{m} / \mathrm{z}$ ratio of 317 for 5-SCD and 212 for the internal standard.

The collision energy was optimized in order to reach a maximum intensity for the fragment ion resulting in a minimum response for the molecular ionic species. As for the other parameters, the determination of collision energy was focused on 5-SCD since this analyte has shown a poorer sensitivity than the internal standard. Different intensities of energy were applied in the collision cell producing, for cysdopa: three significant fragment ions of $m / z, 271,228$ and 155 . Fragment ion at $m / z, 271$ was only present at low collision energy $(<10 \mathrm{eV})$ while ion at $\mathrm{m} / \mathrm{z}$ 228 was detected until an energy of $20 \mathrm{eV}$. The MS/MS transition $317 / 155$ was therefore selected since the ion scan product with $\mathrm{m} / z, 155$ presented systematically the higher abundance. In order to be more selective, the intensity of collision energy was fixed to $25 \mathrm{eV}$. Literature confirms this choice since this ion was described as belonging to the relationship of cysdopa fragment ions obtained after electronic impact and fast atoms bombardment [26]. It was identified as a dihydroxymercaptobenzyle cation. For $\alpha$-methyldopa, a $25 \mathrm{eV}$ collision energy produced significant fragment ions with $\mathrm{m} / \mathrm{z}$ ranging from 93 to 166 . The fragment ion with the highest $\mathrm{m} / \mathrm{z}$ ratio $(\mathrm{m} / \mathrm{z}, 166)$ presented a high intensity and could be selected for quantitative MS detection in the multiple reaction monitoring (MRM) mode in order to avoid interferences.

As MRM is based on the transition involving the specific molecular ion and a characteristic fragment ion, high detection selectivity as well as high signal-to-noise ratios could be obtained providing a clean RP-LC-MS-MS/MRM chromatogram. This detection mode is far more specific than the electrochemical detection which has been used since then to determine 5-SCD. It is also sensitive since a level of $1.6 \mathrm{ng} / \mathrm{ml}$ of 5-SCD in plasma was detectable. Reference values generally admitted are 1.6 and $3.2 \mathrm{ng}$ of 5-SCD by milliliter of plasma, corresponding, respectively, to the maximum of normal values and to the pathological threshold.

In order to obtain an optimal sensitivity, a complete separation of 5-SCD, its internal standard and other catecholamines was performed prior to MS detection.

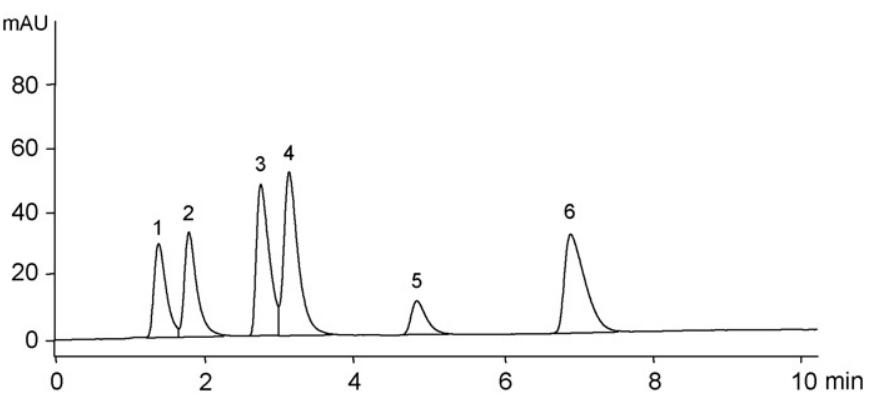

Fig. 2. Chromatogram illustrating the separation of cysteinyldopa from endogenous catecholamines, levodopa (anti-parkinsonian agent) and $\alpha$-methyldopa (internal standard) by LC-UV with gradient elution. LC mobile phase: (A) $0.1 \%$ formic acid in water and (B) $0.1 \%$ formic acid in methanol. Sample: catecholamines $(10 \mu \mathrm{g} / \mathrm{ml})$ in (A). Peaks (1) norepinephrine; (2) epinephrine; (3) dopamine; (4) levodopa; (5) 5-SCD; (6) $\alpha$-methyldopa.

The relatively high polarity of the catecholamines requested the use of mobile phases containing a very low content of organic modifier. The chromatographic separation was first performed on an amidooctadecyl silica stationary phase (HP C18 amide) with a mobile phase containing $1 \%$ of acetonitrile. But when this method was transferred to mass spectrometry, the mobile phase volatilization was found to be difficult. An octadecyl silica stationary phase particularly adapted to aqueous mobile phases (Atlantis dC18) was then tested. The first experimental conditions involved the use of a mobile phase composed of a mixture of $100 \mathrm{mM}$ ammonium formate/water/acetonitrile $(10: 85: 5, \mathrm{v} / \mathrm{v} / \mathrm{v})$ in the isocratic mode but no catecholamine was separated from each other. Resolution was only obtained after removing the organic modifier. However, in order to obtain a sufficient volatilization of the mobile phase after transfer of the method to mass spectrometry, a minimum content in organic modifier was needed. Complete separation of cysdopa and its internal standard was finally achieved by gradient elution. The aqueous fraction of the mobile phase was composed of water containing $0.1 \%$ of formic acid while the organic part was a solution of methanol containing $0.1 \%$ of formic acid. The content in organic modifier increased from 0 to $10 \%$ in $10 \mathrm{~min}$. As can be seen in Fig. 2, the retention times were approximately 5 and 7 min for 5-SCD and $\alpha$-methyldopa, respectively, making the content in methanol sufficient to ensure a satisfactory volatilization of the mobile phase.

\subsection{Optimization of the solid phase extraction procedure}

Prior to LC analysis, an automated solid phase extraction procedure was selected for plasma sample clean-up in order to eliminate endogenous compounds that might interfere with the quantification. Moreover, an increase of the analyte concentrations could be obtained after application of this technique.

Structurally similar to catecholamines, 5-SCD presents a catechol ring, a phenyl substituted by two hydroxyl groups on positions 3 and 4, carrying an ethylamine chain on the first carbon atom. Considering this property, the choice of the extraction sorbent was aimed towards a silica phase bonded with phenylboronic groups which form covalent bindings with 
Table 1

Influence of the presence of TBA in the conditioning buffer and in the sample solution on the recoveries

\begin{tabular}{lll}
\hline & \multicolumn{2}{l}{ Recoveries $(\%) \pm \mathrm{SD}(n=2)$} \\
\cline { 2 - 3 } & Cysdopa & Methyldopa \\
\hline Initial conditions (IC) & $33.4 \pm 1.0$ & $19.9 \pm 2.8$ \\
IC + TBA 5 mM & $83.7 \pm 6.8$ & $90.9 \pm 3.5$ \\
\hline
\end{tabular}

Data obtained on Bond Elut PBA cartridges; initial conditions as given in Section 2; UV detection at $293 \mathrm{~nm}$.

vicinal diols leading to ester formation. Because of the high sensibility of 5-SCD to oxidation, the experiments had to be performed under shelter from light, at a temperature of $4{ }^{\circ} \mathrm{C}$ and with addition of anti-oxidative substances: $4 \mathrm{mM}$ reduced glutathione (GSH) and $5 \mathrm{mM}$ ethylenediaminetetraacetic diammonium salt $\left(\left(\mathrm{NH}_{4}\right)_{2} \mathrm{EDTA}\right)$. The buffer used in the different steps of the extraction process was constituted of $100 \mathrm{mM}$ Tris(hydroxymethyl)aminoethane (Tris buffer) containing these two anti-oxidative substances. The elution solution was composed of a mixture of $3 \mathrm{M}$ formic acid containing $4 \mathrm{mM} \mathrm{GSH}$ adjusted to $\mathrm{pH} 1.5$ with ammonia and acetonitrile in a 95:5 (v/v) ratio. Low recoveries were obtained for levodopa, 5-SCD and $\alpha$-methyldopa due to losses during the washing step (Table 1). This phenomenon has been already observed by Hartleb et al. [16]. Higher recoveries for these compounds in aqueous solution were only obtained by addition of tetrabutylammonium chlorure salt (TBA) to all the extraction process steps (Table 1). The content in TBA was further optimized in order to improve the recoveries. Addition of $2 \mathrm{mM}$ of TBA gave rise to excellent recoveries of analytes in plasma samples with UV detection (91.4 \pm 0.6 and $88.5 \pm 0.3$ (mean $(\%) \pm \mathrm{SD} ; n=2$ ) for 5-SCD and $\alpha$-methyldopa, respectively). Unfortunately, those conditions could not lead to reproducible responses when transferred in mass spectrometry, due to ion suppression effects (probably coming from TBA, GSH and EDTA).

Other types of sorbents, involving the use of more compatible components to MS demands, were then tested. Three kinds of sorbent providing a dual retention mechanism with both nonpolar and strong ion exchange functionalities (Oasis MAX, Isolute HCX-3, Oasis MCX) were evaluated (Table 2). The extraction support differed on the one hand by the nature of the ionized compounds involved in the exchange mechanism, anions for MAX and cations for HCX and MCX. Both exchangers could be employed since the analytes contain amino and carboxylic groups (Fig. 1). On the other hand, the nature of the sorbent

Table 2

Influence of the type of mixed-mode extraction sorbents on the recoveries (\%) of cysdopa and the internal standard in aqueous solution

\begin{tabular}{lll}
\hline \multirow{2}{*}{ Type of sorbent } & \multicolumn{2}{l}{ Analyte recovery $(\%) ; n=2$} \\
\cline { 2 - 3 } & Cysdopa & $\alpha$-Methyldopa \\
\hline MAX & 1.5 & 47.4 \\
HCX-3 & 1.2 & 13.0 \\
MCX & 27.8 & 81.4 \\
\hline
\end{tabular}

Initial conditions for Oasis MAX or Isolute HCX-3 and Oasis MCX as given in Section 2; UV detection at $293 \mathrm{~nm}$. was also different, silica for HCX and polymer composed of hydrophilic $N$-vinylpyrrolidone and lipophilic divinylbenzene for MAX and MCX. In addition to the resistance to extreme $\mathrm{pH}$, a balanced ratio of these two monomers provides an excellent retention for polar compounds and a three-fold higher relative retention capacity when compared with traditional silica-based sorbent like $\mathrm{C} 18$. The $\mathrm{p} K_{\mathrm{a}}$ values, corresponding to a carboxylic group, and an amino group, were 2 and 9.4 for 5-SCD, respectively, and 2.2 and 10.6 for $\alpha$-methyldopa. In order to obtain good retention and elution conditions, a $\mathrm{pH}$ value of 2.5 was chosen in first intention for conditioning, loading and washing the HCX or MCX supports while the elution was performed with methanol containing $2 \%$ of ammonia. The anionic exchanger was tested with $\mathrm{pH} 9$ buffer for the whole procedure but the elution was performed with methanol containing $2 \%$ of acetic acid.

As can be seen in Table 2, the application of aqueous samples on the MAX support gave rise to low recoveries. This can be partially explained by losses of analytes observed during the extraction process (during the loading and the washing steps). On the other hand, no loss of 5-SCD and/or $\alpha$-methyldopa (during the loading and the washing steps) was observed when the sorbent was a polymeric phase instead of bonded silica. MCX cartridges were therefore selected as extraction support and more drastic $\mathrm{pH}$ conditions $(0.1 \mathrm{M} \mathrm{HCl})$ were applied for the conditioning and the washing steps.

Nevertheless, recoveries remained relatively low due to incomplete elution of analytes. For that reason, the optimal composition of the elution solution was investigated. Among the different organic solvents evaluated for the elution step (acetonitrile, methanol, isopropanol and ethyl acetate), methanol gave rise to better results (data not shown). To further improve the analyte recovery, ammonia was chosen as counter-ion because of its perfect volatility and, therefore, its compatibility with mass spectrometry. The influence of the content of ammonia in the elution solution on the recoveries of 5-SCD was investigated in aqueous solution (Fig. 3) and the best results were obtained for 2,5 and $10 \%$ of ammonia. Since no significant difference was observed, a content of $10 \%$ in ammonia was selected in order to ensure the strongest elution of the analytes. Fig. 3 also illustrates the analyte recovery obtained after addition of water in the

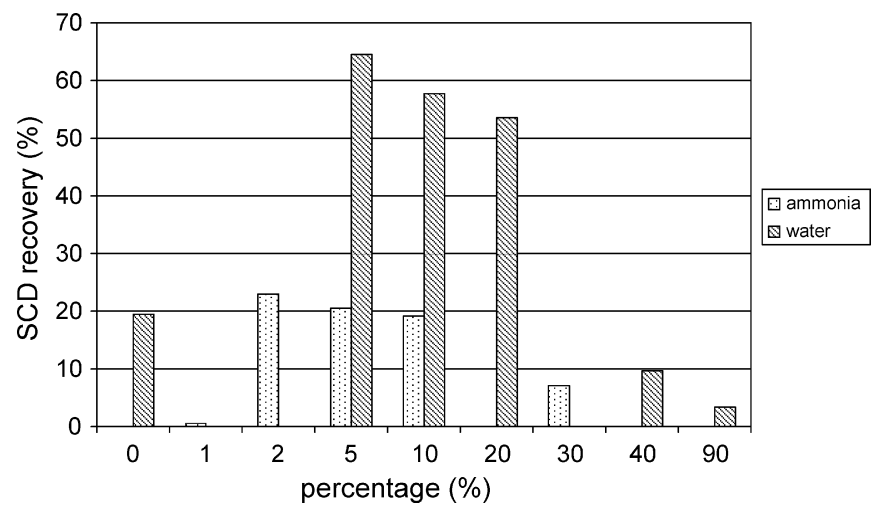

Fig. 3. Influence of the composition of the elution solution on the recovery of cysdopa (\%): (i) content of ammonia in methanol (ammonia) and (ii) content of water in a mixture of methanol and $10 \%$ of ammonia (water); extraction support: Oasis MCX. Other conditions as given in Section 2. 

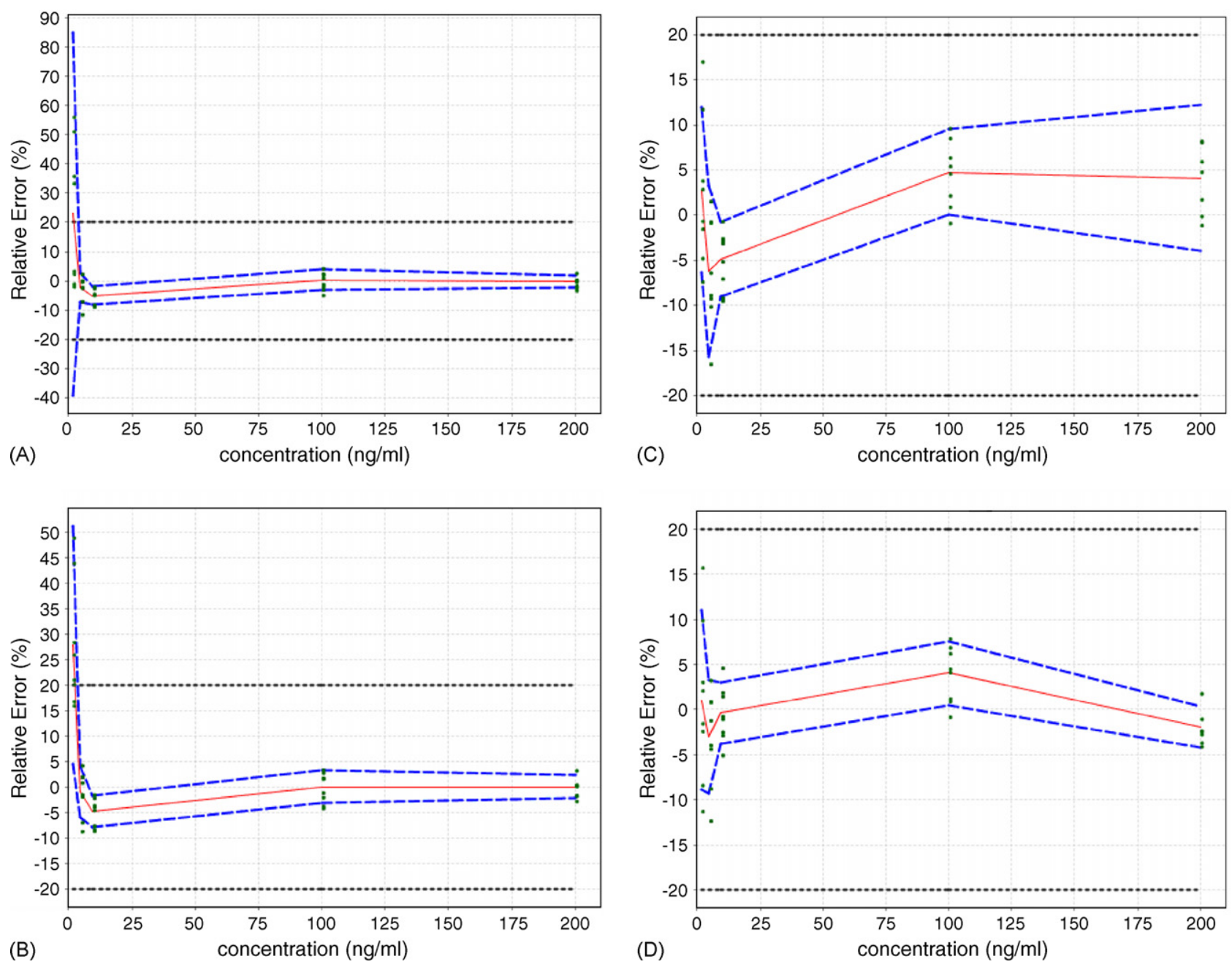

Fig. 4. Accuracy profile obtained by considering: (A) linear regression, (B) quadratic regression, (C) weighted $1 / x^{2}$ linear regression and (D) weighted $1 / x^{2}$ quadratic regression; plain line: relative bias, dashed lines: $\beta$-expectation tolerance limit, dotted curves: acceptance limit (20\%) and green dots: relative back-calculated concentrations.

elution solution. 5 and $10 \%$ of water led to a three-fold increase of the analyte recovery. More reproducible results with $10 \%$ of water were obtained for the handling of plasma samples (data not shown). Due to the instability of catecholamines and particularly 5-SCD in basic conditions, an anti-oxidative substance, ascorbic acid, at a concentration of $0.1 \%$ was finally introduced in the eluting mixture before the eluting step giving rise to better recoveries, $88.9 \pm 1.1$ and $93.3 \pm 1.5$ (mean $(\%) \pm \mathrm{SD} ; n=2)$ for 5-SCD and $\alpha$-methyldopa, respectively, in aqueous solution and by applying UV detection. Finally, the application of the whole SPE-LC-MS-MS method to spiked plasma samples led to excellent recoveries for cysdopa: $80.4 \pm 3.0$ (mean $(\%) \pm$ SD; $n=20$ ).

\subsection{Stability}

The sensitivity of 5-SCD against oxidation and light was taken into consideration from the beginning of the procedure. Indeed, for the standard solution, we always worked with $10 \mathrm{mM}$ hydrochloric acid solution in which 5-SCD and the catecholamines were proven to be stable for at least 4 months at $-80^{\circ} \mathrm{C}$ (data not shown). The spiked plasma samples were previously acidified by $2 \%$ phosphoric acid, which guarantees the stability of the compound of interest.

5-SCD was in the presence of alkaline solution only during a very short period of time (less than $1 \mathrm{~min}$ ) corresponding to the elution step on the MCX cartridges, but oxidation phenomenon could be avoided thanks to the addition of ascorbic acid in the elution solution and immediate acidification of the eluate with formic acid (cf. Section 2).

During all the SPE and the LC-MS-MS procedures, the samples were stored at $4{ }^{\circ} \mathrm{C}$ and in the darkness.

\subsection{Method prevalidation}

An original approach using accuracy profiles based on tolerance intervals for the total measurement error, including both bias and standard deviation for intermediate precision, was applied to demonstrate the method capability to quantify $[27,28]$. For this approach two parameters must be set, the acceptance limits on one hand and the risk of having future measurements falling outside those acceptance limits on the other hand. The 
Table 3

Prevalidation results

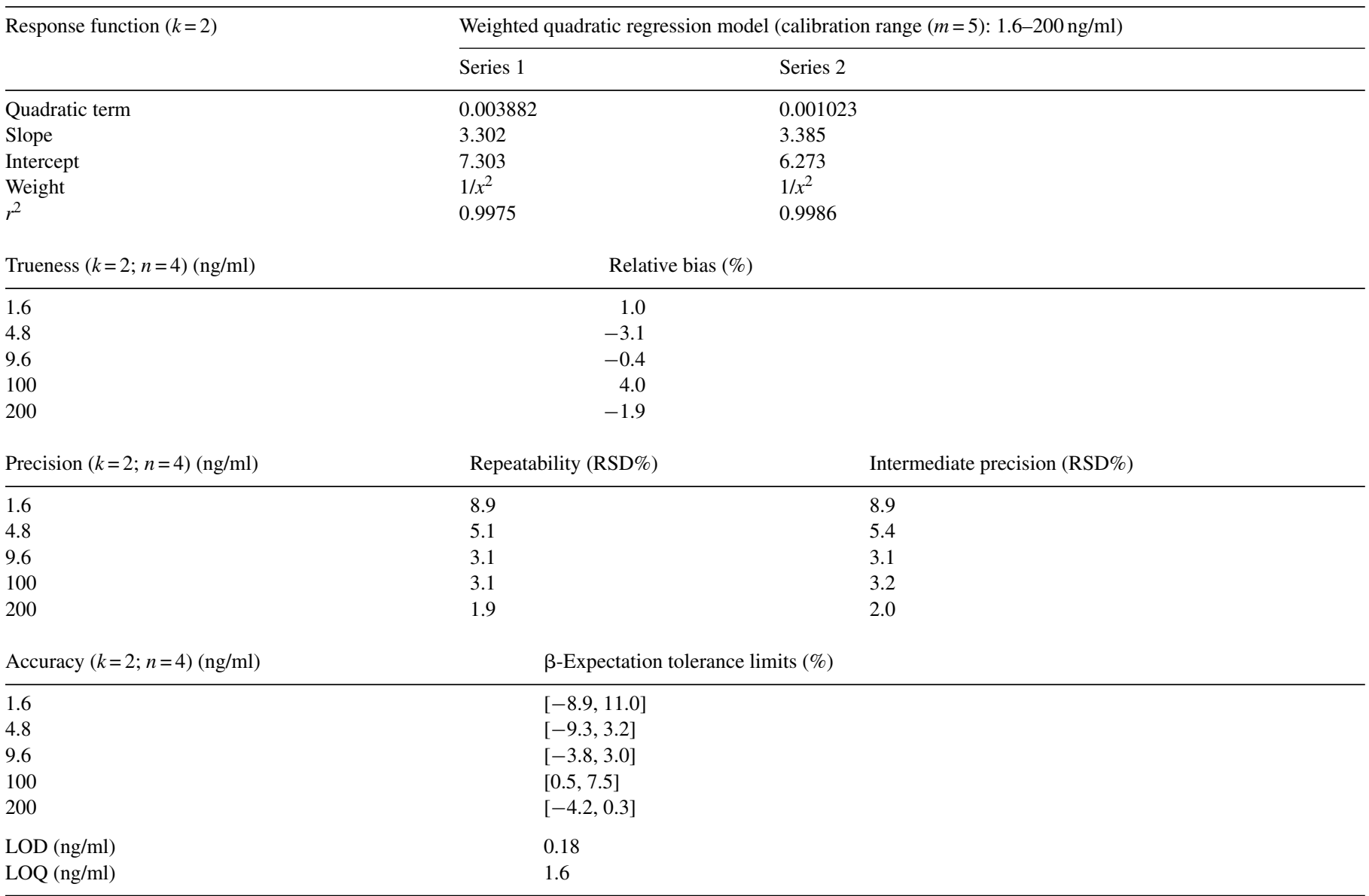

$k$ : Number of days of experiments (series); $m$ : number of concentration levels; $n$ : number of replicates per concentration level and per series.

acceptance limits were set at $\pm 20 \%$ as proposed by the FDA document [29]. In the same document, for the in-study validation, a run is accepted by applying the 4-6-20 rule, i.e. at least 4 results out of 6 must be within the acceptance limits of $\pm 20 \%$. In other words this means that the risk of having results falling outside the acceptance limits accepted during routine analysis is equal to $33.33 \%$. In order to make the prevalidation in agreement with this routine analysis acceptance rule, the risk was therefore set at $33.33 \%$ in the present study.

To prevalidate the analytical procedure, the standard addition method had to be used. Indeed the analyte studied is naturally present in the matrix. Therefore, calibration curves were made by spiking plasma in order to reach 5 concentration levels ranging form 1.6 to $200 \mathrm{ng} / \mathrm{ml}$ of added 5-SCD. For each calibration curve four calibration standards were analyzed at each concentration level for 2 days. Quadratic and linear regression models were fitted as well as the weighted by $1 / x^{2}$ quadratic and linear models to look for the most adequate response function. To achieve this, the concentrations of the calibration standards were back-calculated using each regression model in order to determine, by concentration level, the mean relative bias, the standard deviation intermediate precision as well as the upper and lower $\beta$-expectation tolerance limits $[27,28,31]$ and therefore draw their respective accuracy profiles [30]. The most suitable regression model for the intended use of the analytical method was selected on the basis of these profiles as shown in Fig. 4. When the acceptance limits were set at $\pm 20 \%$ according to the regulatory requirements [29], only the two weighted regression model allowed demonstrating the capability of the method to quantify 5-SCD over the concentration range considered, since the tolerance intervals were totally included inside the acceptance limits. However the model selected was the weighted $1 / x^{2}$ quadratic regression as it is the one showing the best overall trueness and precision. The response function obtained by applying this regression model is presented in Table 3.

From these results, the concentration of the endogenous 5-SCD was estimated via the responses functions used each day. The estimated concentration of the native 5-SCD was of $2.18 \mathrm{ng} / \mathrm{ml}$. In order to confirm this, four samples of native plasma were analyzed each day and their concentration back-calculated with their respective calibration curve. If this assumption was acceptable then the back-calculated concentration should be close to $0 \mathrm{ng} / \mathrm{ml}$. This was verified by using a Student's $t$-test. Indeed, the back-calculated concentrations were considered not to be different from $0 \mathrm{ng} / \mathrm{ml}$ as the confidence interval of the mean result included the value $0(95 \%$ confidence interval: $[-0.06 ; 0.21])$. 
Trueness $[27,28,32]$ expressed in terms of relative bias (\%) was then assessed from the calibration standards for 5-SCD at 5 concentration levels as can be seen in Table 3. According to the regulatory requirements [29], trueness was acceptable since the bias did not exceed the value of $\pm 15 \%$, irrespective of the concentration level.

The precision of the bioanalytical method was determined by computing the relative standard deviations (RSD) for repeatability and time-different intermediate precision at each concentration level of the calibration standards [27-29]. The RSD values presented in Table 3 were also acceptable as they did not exceed $\pm 15 \%$. These results illustrate the good precision of the developed method.

Accuracy takes into account the total error, i.e. the sum of systematic and random errors, related to the test result [27-29,31,32]. As shown in Table 3, the upper and lower $\beta$ expectation tolerance limits (\%) did not exceed the acceptance limits settled at $\pm 20 \%$ for each concentration level. Consequently, the method can be considered as accurate over the concentration range investigated [27-29]. Therefore, the lower limit of quantitation (LOQ) was $1.6 \mathrm{ng} / \mathrm{ml}$. The limit of detection (LOD) was estimated using the mean intercept of the calibration model and the residual variance of the regression. The LOD was evaluated at $0.18 \mathrm{ng} / \mathrm{ml}$.

\section{Conclusions}

5-SCD in plasma was determined for the first time by a sensitive and selective LC-ESI-MS-MS method. A new extraction method using sorbent filled with a solid phase containing hydrophobic and cation exchange functional groups was finally chosen and optimized. The extreme sensitivity of 5-SCD against oxidation and light was taken into consideration from the beginning of the procedure. Good recoveries were obtained for 5-SCD in plasma samples and accuracy of the method was demonstrated. Because the accuracy profile was within the acceptance limits set at $20 \%$ according to the FDA regulations (Bioanalytical Method Validation: CDER: http://www.fda.gov/cder/guidance) in the concentration range of $1.6-200 \mathrm{ng} / \mathrm{ml}$, it was demonstrated that the analytical method fulfils its objective, that is the accurate quantification of 5-SCD in plasma.

\section{Acknowledgements}

Research grants from the Belgium National Fund for Scientific Research (FNRS) to two of us (P.T. and M.F.) are gratefully acknowledged. Thanks are also due to the Walloon Region and the European Social Fund for a research grant to E.R. (First Europe Objective 3 project no. 215269).

\section{References}

[1] J. Hartleb, R. Arndt, J. Chromatogr. B 764 (2001) 409.

[2] A.C. Buzaid, M.I. Ross, L.M. Balch, S.J. Soong, W.H. Mc Carthy, L. Tinoco, et al., J. Clin. Oncol. 15 (1997) 1039.
[3] S. O’Day, P. Boasberg, Surg. Oncol. Clin. N. Am. 15 (2006) 419.

[4] D.L. Cummins, J.M. Cummins, H. Pantle, M.A. Silverman, A.L. Leonard, A. Chanmugam, Mayo. Clin. Proc. 81 (2006) 500.

[5] L. Brochez, J.-M. Naeyaert, Br. J. Dermatol. 143 (2000) 256.

[6] L.L. Peterson, W.R. Woodward, W.S. Fletcher, M. Palmquist, M.A. Tucker, A. Nias, J. Am. Acad. Dermatol. 19 (1988) 509.

[7] K. Wakamatsu, T. Kageshita, M. Furue, N. Hatta, Y. Kiyohara, T. Ono, T. Saida, M. Takata, T. Tushida, H. Uhara, A. Yamamoto, N. Yamazaki, A. Naito, S. Ito, Melanoma Res. 12 (2002) 245.

[8] T. Banfalvi, K. Gilde, M. Gergye, M. Boldizsar, T. Kremmer, S. Otto, Eur. J. Cancer 39 (2003) 164.

[9] I. Wimmer, J.C. Meyer, B. Seifert, R. Dummer, A. Flace, G. Burg, Cancer Res. 57 (1997) 5073.

[10] C. Hansson, L.-E. Edholm, G. Agrup, H. Rorsman, A.-M. Rosengren, E. Rosengren, Clin. Chim. Acta 88 (1978) 419.

[11] B. Kagedal, A. Pettersson, J. Chromatogr. 272 (1983) 287.

[12] F. Hu, W.R. Woodward, L.L. Peterson, J. Investig. Dermatol. 90 (1988) 149.

[13] S. Ito, T. Kato, K. Maruta, K. Fujita, T. Kurahashi, J. Chromatogr. 311 (1984) 154

[14] K. Arstrand, A. Kullman, R. Andersson, T. Rasmuson, B. Kagedal, Scand. J. Clin. Lab. Invest. 64 (2004) 559.

[15] C. Hansson, B. Kagedal, M. Kallberg, J. Chromatogr. 420 (1987) 146.

[16] J. Hartleb, Y. Damm, R. Arndt, E. Christophers, E. Stockfleth, J. Chromatogr. B 727 (1999) 31

[17] T. Huang, J. Wall, P. Kabra, J. Chromatogr. 452 (1988) 409.

[18] T. Banfalvi, K. Gilde, M. Boldizsar, Z. Fejös, B. Horvath, G. Liszkay, E. Beczassy, T. Kremmer, Eur. J. Clin. Investig. 30 (2000) 900.

[19] K. Wakamatsu, S. Ito, Clin. Chem. 40 (1994) 495.

[20] B. Kagedal, M. Kallberg, K. Arstrand, C. Hansson, J. Chromatogr. 473 (1989) 359.

[21] K. Wakamatsu, M. Yokochi, A. Naito, T. Kageshita, S. Ito, Melanoma Res. 13 (2003) 357.

[22] T. Banfalvi, K. Gilde, M. Boldizsar, Z. Fejos, B. Horvath, G. Liszkay, E. Beczassy, T. Kremmer, Eur. J. Clin. Investig. 30 (2000) 900.

[23] K. Arstrand, A. Kullman, R. Andersson, T. Rasmuson, B. Kagedal, Scand. J. Clin. Lab. Investig. 64 (2004) 559.

[24] G. Prota, G. Scherillo, R.A. Nicolaus, Gazz. Chim. Ital. 98 (1968) 495.

[25] S. Ito, S. Inoue, Y. Yamamoto, K. Fujita, J. Med. Chem. 24 (1981) 673.

[26] M. d'Ischia, A. Pezzella, D. Favretto, P. Traldi, G. Prota, J. Mass Spectrom. 31 (1996) 885.

[27] Ph. Hubert, J.-J. Nguyen-Huu, B. Boulanger, E. Chapuzet, P. Chiap, N. Cohen, P.-A. Compagnon, W. Dewe, M. Feinberg, M. Lallier, M. Laurentie, N. Mercier, G. Muzard, C. Nivet, L. Valat, STP Pharma Pratiques 13 (2003) 101.

[28] Ph. Hubert, J.-J. Nguyen-Huu, B. Boulanger, E. Chapuzet, P. Chiap, N. Cohen, P.-A. Compagnon, W. Dewe, M. Feinberg, M. Lallier, M. Laurentie, N. Mercier, G. Muzard, C. Nivet, L. Valat, J. Pharm. Biomed. Anal. 36 (2004) 579 .

[29] Guidance for Industry: Bioanalytical Method Validation, US Department of Health and Human Services, Food and Drug Administration, Center for Drug Evaluation and Research (CDER), Center for Biologics Evaluation and Research (CBER), May 2001.

[30] Ph. Hubert, J.J. Nguyen-Huu, B. Boulanger, E. Chapuzet, P. Chiap, N. Cohen, P.A. Compagnon, W. Dewe, M. Feinberg, M. Lallier, M. Laurentie, N. Mercier, G. Muzard, C. Nivet, L. Valat, STP Pharma Pratiques 16 (2006) 30.

[31] Ph. Hubert, P. Chiap, J. Crommen, B. Boulanger, E. Chapuzet, N. Mercier, S. Bervoas-Martin, P. Chevalier, D. Grandjean, P. Lagorce, M. Lallier, M.C. Laparra, M. Laurentie, J.C. Nivet, Anal. Chim. Acta 391 (1999) 135.

[32] ISO 5725-1, Application of the Statistics-Accuracy (Trueness and Precision) of the Results and Methods of Measurement-Part 1: General Principles and Definitions, International Organization for Standardization (ISO), Geneva, Switzerland. 